\title{
Methadone associated long term hearing loss and nephrotoxicity; a case report and literature review
}

\author{
Saeedeh Ghasemi ${ }^{1}$, Shadi Izadpanahi ${ }^{2}$, Mohammad Ali Yaghoubi ${ }^{3}$, Jeffrey Brent ${ }^{4}$ and Omid Mehrpour ${ }^{1,5^{*}}$ (D)
}

\begin{abstract}
Background: Methadone is a long-acting opioid receptor agonist. Reported adverse effects of methadone include constipation, respiratory depression, dizziness, nausea, vomiting, itching, sweating, rhabdomyolysis, QT prolongation, and orthostatic hypotension. Hearing loss has been rarely reported following methadone use, and when reported, long term follow-up is rare.

Herein we report a case of methadone poisoning with rhabdomyolysis, acute kidney injury, and persistent hearing loss documented by a 2 year follow up.

Case presentation: The patient was a 34 years old male who presented with a reduced level of consciousness and acute hearing loss after suicidal ingestion of $40 \mathrm{mg}$ of methadone while experiencing family-related stresses. He had no prior history of methadone use, abuse, or addiction.

Initial laboratory testing was significant for a serum creatinine concentration of $4.1 \mathrm{mg} / \mathrm{dl}$, a mixed metabolic and respiratory acidosis, thrombocytopenia, abnormal hepatic transaminases, and coagulation tests. The patient then developed severe rhabdomyolysis. Also, audiometry showed a bilateral sensorineural hearing loss. The patient required hemodialysis for 11 days while his metabolic abnormalities gradually resolved. However, his hearing loss was persistent, as demonstrated by 2 years of follow up.

Conclusion: Our patient simultaneously had kidney failure, rhabdomyolysis, and permanent hearing loss following methadone poisoning. Although rare, ototoxicity and permanent hearing loss may happen in cases of methadone poisoning. While opioid-induced hearing loss is uncommon, methadone toxicity should be taken into account for any previously healthy patient presenting with acute hearing loss with or without rhabdomyolysis.
\end{abstract}

Keywords: Rhabdomyolysis, Hearing loss, Methadone, poisoning

\section{Background}

Methadone is a synthetic $\mu$-opioid receptor agonist used in the treatment both of pain and opioid dependence [1-4]. In the last decade, the amounts of opioids prescribed, and the consequent death rate and abuse of these drugs, has dramatically increased [5].

Rapidly progressive sensorineural hearing loss has been rarely reported in opioid analgesic users, including those using methadone [6-8]. The mechanism of this

\footnotetext{
* Correspondence: omid.mehrpour@yahoo.com.au

${ }^{1}$ Medical Toxicology and Drug Abuse Research Center (MTDRC), Birjand

University of Medical Sciences, Ghaffari Avenue, Vali-Asr hospital, Birjand, Iran

${ }^{5}$ Rocky Mountain Poison and Drug Safety, Denver Health and Hospital

Authority, 1391 Speer Blvd, Denver, CO 80204, USA

Full list of author information is available at the end of the article
}

hearing loss is not well understood. Suggested causes include ischemia [9], genetic predisposition [10], direct cochlear toxicity [11], and hypersensitization that manifests upon re-exposure after a period of opioid withdrawal $[12,13]$. Most of the reported cases recover after a period of opioid abstinence [11]. Although hearing loss due to methadone poisoning is rare, it is generally transient [14]. Apparent permanent hearing loss due to methadone poisoning is infrequent [14]. However, for the reported cases there is often a lack of long-term follow-up. Here, we report a case of long-term follow-up of a patient with permanent bilateral sensorineural hearing loss after a methadone overdose complicated by rhabdomyolysis and severe acute kidney injury.

(c) The Author(s). 2019 Open Access This article is distributed under the terms of the Creative Commons Attribution 4.0 International License (http://creativecommons.org/licenses/by/4.0/), which permits unrestricted use, distribution, and reproduction in any medium, provided you give appropriate credit to the original author(s) and the source, provide a link to the Creative Commons license, and indicate if changes were made. The Creative Commons Public Domain Dedication waiver (http://creativecommons.org/publicdomain/zero/1.0/) applies to the data made available in this article, unless otherwise stated. 


\section{Case presentation}

A 34-year-old male presented to the Emergency Department with a reduced level of consciousness and hearing loss $21 \mathrm{~h}$ after ingesting a $40 \mathrm{mg}$ methadone tablet in a suicide attempt in front of his family after a serious conflict with his father. The family denied any history of a psychiatric disorder or prior methadone use. Prehospital emergency service administered $0.4 \mathrm{mg}$ of naloxone due to apneustic breathing and miotic pupils, which resulted in a marked improvement in the patient's breathing. He and his family denied any specific drug abuse history. He smoked cigarettes but did not use alcohol. Before this suicide attempt, he was healthy without any significant past medical history and did not have any known auditory deficits.

On admission to the Emergency Department (ED) the patient was lethargic, had miotic pupils and the following vital signs: blood pressure $110 / 70 \mathrm{mmHg}$, heart rate 110 beats per minute, respiratory rate 16 breaths per minute, temperature $37^{\circ} \mathrm{C}$, oxygen saturation while receiving 81 oxygen per minute by nasal cannula $89 \%$. At the time of admission to the ED and he complained of bilateral hearing loss. His urine was noted to be dark, and a rapid urine toxicology screen test was positive for methadone but was negative for amphetamines, barbiturates, benzodiazepines, cocaine, morphine, phencyclidine, and tetrahydrocannabinol. Blood acetaminophen, salicylate, and ethanol assays were negative.

Initial laboratory studies showed a mixed metabolic and respiratory acidosis (pH 7.11, PCO2 $41.8 \mathrm{mmHg}$, HCO3 $13.5 \mathrm{mmol} / \mathrm{l}$ ), aspartate aminotransferase (AST) $1417 \mathrm{U} / \mathrm{L}$, alanine aminotransferase (ALT) $1125 \mathrm{U} / \mathrm{L}$, BUN $85 \mathrm{mg} / \mathrm{dL}$, Cr $4.1 \mathrm{mg} / \mathrm{dL}$, international normalized ratio (INR) 2.24, and Platelet count of $66,115 / \mathrm{mm}^{3}$
(Table 1). The microscopic examination of his peripheral blood smear was normal.

Initial treatment consisted of the administration of intravenous fluids and sodium bicarbonate. Twelve hours post-admission, the patient was transferred to the Intensive Care Unit (ICU), where he received a naloxone infusion for 3 days.

On admission to the ICU, SPO2, while using an oxygen mask at $81 /$ minute was $97 \%$, and his arterial blood gas assay showed: pH 7.33, PCO2 $43.1 \mathrm{mmHg}$, and serum $\mathrm{HCO} 323 \mathrm{mmol} / \mathrm{l}$.

On the following day, he was alert and breathing normally with a leukocytosis of 14,116 cells/microliter (mcl) (Table 1), but no evidence of infection or fever. No antibiotics were administered. His creatine phosphokinase (CPK) was found to be 97,231 U/L. He continued to demonstrate hearing impairment and audiometry showed a bilateral sensorineural hearing loss (Fig. 1).

By the third day of admission, the patient complained of myalgia and had a urine output of approximately $100 \mathrm{ml} / 24 \mathrm{~h}$, a BUN of $170 \mathrm{mg} / \mathrm{dL}$, serum creatinine of $7.1 \mathrm{mg} / \mathrm{dL}$, and a serum uric acid $11 \mathrm{mg} / \mathrm{dL}$. Nonheparinized hemodialysis was initiated. Kidney sonography was suggestive of parenchymal kidney disease and acute tubular necrosis. He required hemodialysis for 11 days.

During 10 days of admission to the ICU, his hepatic transaminases and CPK gradually normalized (Table 1).

The patient was transferred to the internal medicine ward on day 11. During the 5 days of hospital stay in the internal ward, the patient's hearing loss continued despite the normalization of his laboratory studies. He was discharged after 15 days of hospitalization. After 2 years of follow-up, his hearing loss persisted.

Table 1 Laboratory finding during admission of case

\begin{tabular}{|c|c|c|c|c|c|c|c|c|c|c|c|}
\hline Day of admission & 1 & 2 & 3 & 4 & 5 & 7 & 8 & 9 & 10 & 13 & 15 \\
\hline WBC & 10,150 & 14,116 & & 10,400 & 7300 & 12,700 & 13,910 & & 14,150 & 10,300 & 6210 \\
\hline PLATELET & 66,115 & & & 110,000 & & & & & 150,405 & 192,000 & 180,300 \\
\hline CPK (U/L) & & 97,231 & & 77,150 & 20,400 & 6087 & 1456 & 1389 & 803 & 556 & 120 \\
\hline Alkaline Phosphatase (U/L) & 330 & & & 234 & & 361 & 427 & 303 & 265 & 300 & 180 \\
\hline PT (Second) & 22 & 20.1 & 16.8 & 13 & 14 & 13.8 & 15.5 & 18 & 15.6 & 17 & 14 \\
\hline PTT (Second) & 37 & 25 & 31.7 & 26 & 24 & 27.5 & 25 & 32 & 32 & 29 & 25 \\
\hline INR & 2.24 & 1.91 & 1.42 & 0.94 & 1.06 & 1.02 & 1.26 & 1.6 & 1.26 & 1.5 & 1.1 \\
\hline $\mathrm{BUN}(\mathrm{mg} / \mathrm{dL})$ & 85 & 155 & 170 & 245 & 276 & 206 & 151 & 130 & 170 & 90 & 24 \\
\hline $\mathrm{Cr}(\mathrm{mg} / \mathrm{dL})$ & 4.1 & 6.2 & 7.1 & 9.1 & 10.8 & 9.8 & 8 & 6.6 & 3.8 & 2 & 1.4 \\
\hline AST (U/L) & 1417 & & 1800 & 1415 & 670 & 220 & 180 & 110 & 80 & 90 & 43 \\
\hline Uric Acid (mg/dL) & 11 & & 11 & 8 & & & 7 & & 6 & 6 & 3 \\
\hline $\mathrm{ALT}(\mathrm{U} / \mathrm{L})$ & 1125 & & 1203 & 1610 & 500 & 480 & 310 & 179 & 115 & 45 & 30 \\
\hline
\end{tabular}

Abbreviations: WBC White blood cell, CPK Creatine phosphokinase, PT Prothrombin time, PTT Partial thromboplastin time, INR International normalized ratio, BUN Blood urea nitrogen, $\mathrm{Cr}$ Creatinine, AST Aspartate aminotransferase, ALT Alanine aminotransferase 


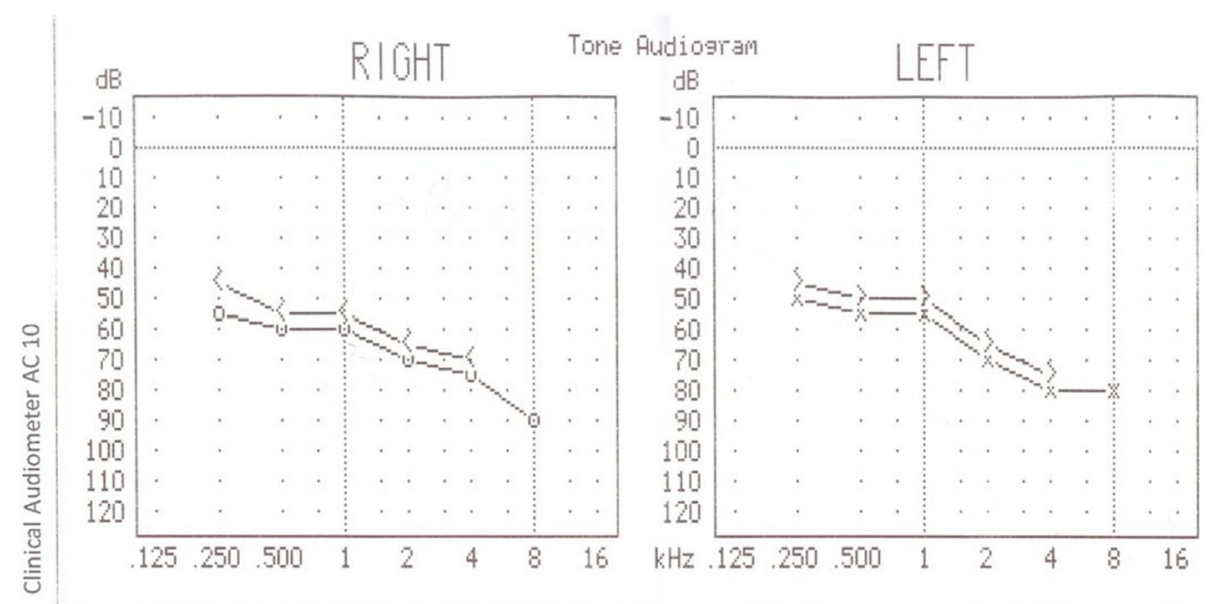

Fig. 1 Audiometry performed on the patient on the second day of admission

\section{Discussion}

Here we report a case of methadone poisoning following a suicide attempt with a 40-mg tablet of methadone who exhibited rhabdomyolysis, acute renal failure, and chronic bilateral sensorineural hearing loss. Unlike most prior cases, our patient's hearing loss persisted despite the normalization of his renal function and resolution of his metabolic abnormalities.

Sudden sensorineural hearing loss has several potential causes, including infections, autoimmune diseases, trauma, vascular disorders, and neoplastic diseases, but most cases are idiopathic [15]. Many of these cases are caused by autoimmune processes or, in rare cases, medications, including some antibiotics (such as aminoglycosides), diuretics, chemotherapeutic agents, and anti-inflammatory drugs $[16,17]$.

Ototoxicity is a known rare complication of opioid use. In 1979, Mulch et al. reported the first case of opioid-induced hearing loss, which was associated with hydrocodone abuse. Since then, several case reports have described both reversible and irreversible bilateral hearing loss following hydrocodone/acetaminophen [6], oxymorphone [11], propoxyphene [18, 19] and heroin abuse [12, 20-23]. Hearing loss following methadone use has been occasionally reported [8]..

In 2009, the first case of bilateral hearing loss due to methadone was reported in a 37-year-old man who overdosed on $75 \mathrm{mg}$ methadone tablets [24]. Thier patient, with no previous history of an auditory disease, had hearing loss and tinnitus, which resolved in 10 days.

Subsequently, a number of patients have been reported to develop hearing loss after methadone use $[8,13,16,24,25]$. Most of the reported cases of methadone-induced hearing loss were transient and recovered within $\mathrm{t} 10$ days of ingestion [13, 24, 25]. Very few cases reported long term hearing loss after methadone ingestion [8, 16]. Vorasubin et al. [8] first reported persistent bilateral sensorineural hearing loss following methadone ingestion in a 23 years old man, which after 9 months of follow up was deemed permanent. Saifan et al. [16] reported severe sensorineural hearing loss in a 31year-old male who showed a persistent hearing loss after 2 months of follow up. He was prescribed binaural hearing aids. Our case had 2 years of follow up. Given the lack of resolution during this period, it is likely that his hearing loss is permanent.

The mechanism through which opioids cause hearing loss has not been adequately explained. Among the theories that have been offered for this complication is the contamination of the drug with unknown materials. However, this theory is more likely for heroin-induced sensorineural hearing loss, since methadone is usually produced in pharmaceutical laboratories [16].

Another theorized mechanism for opioid-associated hearing loss is hypoperfusion of the vestibulocochlear system secondary to opioid-induced vasospasm or vasculitis. The origin of this theory is the observation of cerebral infarcts following heroin used due to the resulting vasculitis [8, 22]. However, here too, vasculitis from a pharmaceutical preparation is less likely. Alternatively, genetic polymorphism in drug metabolism has been postulated to cause opioid-induced hearing loss. This theory posits that some people are prone to hearing loss following opioid use and may even experience it after the usual therapeutic doses of opioids, while others develop hearing loss only after taking higher doses of opioids [8]. Another theory of this disorder is the direct cochlear damage by agonism at opioid receptors. Animal studies have indicated that opioid $\mu, \delta$, and $\kappa$ receptors have been found on the cochlea [26, 27]. Poisoning with opioids leads to over-stimulation of the kappa receptor and decreases the activity of the cochlear hair cells [28]. Also, 
when the $\mu$ receptors in the cochlea bind to their agonists, they decrease the activity of adenylate cyclase and alter signal transduction [8].

Our patient had metabolic acidosis, rhabdomyolysis, and acute renal failure requiring hemodialysis. Rhabdomyolysis is a serious syndrome caused by the breakdown of skeletal muscle fibers followed by leakage of muscle contents into the patient's circulation [29]. The causes of rhabdomyolysis include the traumatic and non-traumatic injury of muscles, drugs, toxins, infections, and electrolyte disturbances [30], but the development of rhabdomyolysis following opioid poisoning has only been reported in a few cases [28-31]. The hypotheses that have been raised for the cause of rhabdomyolysis in opioid users include dehydration, vascular insufficiency, muscle contraction, vasospasm, shock, trauma, seizure, acidosis, respiratory failure, and direct effects of the opioid [3, 25]. Concomitant of rhabdomyolysis and hearing loss following opioid poisoning as in our patient was rarely reported [28].

Surprisingly, rhabdomyolysis and acute kidney injury were in the first day after ingestion in our case. Rapid onset of rhabdomyolysis and acute kidney injury following methadone poisoning has rarely reported [31, 32]. Likely, coma, immobilization, volume depletion and direct effect of methadone on the kidney were responsible. Similar to our case, Saifan et al. [16] reported hearing loss still present 2 months after concomitant with transient kidney failure after methadone ingestion. The relationship between these complications is unclear, but the similarity between the channels and the junctions between stria vascularis and kidney tubules is a possible explanation [8]. Further studies may more accurately identify the mechanisms that lead to these complications and their predisposing causes.

\section{Conclusion}

Methadone poisoning may induce rhabdomyolysis, acute kidney injury, and permanent hearing loss. Although most ototoxicity due to methadone poisoning is manifested as transient hearing loss, permanent hearing loss may rarely occur. While opioid-induced hearing loss is uncommon, methadone toxicity should be taken into account for any previously healthy patient presenting with acute hearing loss, with or without rhabdomyolysis. The relationship, if any, between rhabdomyolysis and hearing loss, warrants further study.

\section{Abbreviations}

ALT: Alanine aminotransferase; AST: Aspartate aminotransferase; BUN: Blood urea nitrogen; CPK: Creatine phosphokinase; Cr: Creatinine; INR: International normalized ratio; PT: Prothrombin time; PTT: Partial thromboplastin time; WBC: White blood cell

\section{Acknowledgments}

We thank the patient who kindly consented for their medical history and clinical experience to be written up and repurposed for educational use.

\section{Authors' contributions}

SG, SI, and MAY cared for the patient in the emergency department. MAY and $O M$ recognized the specialty of the presented case and thus initiated its publication. SG, SI, MAY, and OM conducted the literature search and drafted the manuscript. OM and JB critically revised the manuscript for important intellectual content. All authors read and approved the final manuscript.

\section{Funding}

It is the outcome of an in-house financially non-supported study.

\section{Availability of data and materials}

The dataset used and analyzed during the current study is available from the corresponding author on reasonable request.

Ethics approval and consent to participate

Not applicable.

\section{Consent for publication}

Written informed consent was obtained from the patient for publication of this case report.

\section{Competing interests}

The authors declare that they have no competing interests.

\section{Author details}

${ }^{1}$ Medical Toxicology and Drug Abuse Research Center (MTDRC), Birjand University of Medical Sciences, Ghaffari Avenue, Vali-Asr hospital, Birjand, Iran. ${ }^{2}$ Student Research Committee, Birjand University of Medical Sciences, Birjand, Iran. ${ }^{3}$ Metabolic Syndrome Research Center, Mashhad University of Medical Sciences, Mashhad, Iran. ${ }^{4}$ Department of Medicine, University of Colorado School of Medicine, Aurora, CO, USA. ${ }^{5}$ Rocky Mountain Poison and Drug Safety, Denver Health and Hospital Authority, 1391 Speer Blvd, Denver, CO 80204, USA.

Received: 4 April 2019 Accepted: 22 October 2019

Published online: 06 November 2019

\section{References}

1. Toce MS, Stefater MA, Breault DT, Burns MM. A case report of methadone-associated hypoglycemia in an 11-month-old male. Clin Toxicol. 2018;56(1):74-6.

2. Alinejad S, Zamani N, Abdollahi M, Mehrpour O. A narrative review of acute adult poisoning in Iran. Iran J Med Sci. 2017:42(4):327.

3. Alinejad S, Ghaemi K, Abdollahi M, Mehrpour O. Nephrotoxicity of methadone: a systematic review. Springerplus. 2016;5(1):2087.

4. Alinejad S, Kazemi T, Zamani N, Hoffman RS, Mehrpour O. A systematic review of the cardiotoxicity of methadone. EXCLI J. 2015;14:577.

5. Paulozzi $L$, Kilbourne EM, Desai HA. Prescription drug monitoring programs and death rates from drug overdose. Pain Med. 2011;12(5):747-54.

6. Friedman RA, House JW, Luxford WM, Gherini S, Mills D. Profound hearing loss associated with hydrocodone/acetaminophen abuse. Otol Neurotol. 2000;21(2):188-91.

7. Ho T. Hydrocodone use and sensorineural hearing loss. Pain Physician. 2007; 10:467-72.

8. Vorasubin N, Calzada AP, Ishiyama A. Methadone-induced bilateral severe sensorineural hearing loss. Am J Otolaryngol. 2013;34(6):735-8.

9. Kopec KT, Nelson LS. Opioid-induced hearing loss: a trend to keep listening for. Emerg Med. 2012;44(11):4-6.

10. Benyamin R, Trescot A, Datta S. Opioid complications and side effects. Pain Physician J. 2008;11:S105-S20.

11. MacDonald LE, Onsrud JE, Mullins-Hodgin R. Acute sensorineural hearing loss after abuse of an inhaled, crushed oxymorphone extended-release tablet. Pharmacotherapy. 2015;35(7):e118-e21.

12. Kortequee S, Agada F, Coatesworth A. Sudden sensorineural hearing loss following intracarotid injection of heroin. Int J Clin Pract. 2005;59:128-9.

13. Shaw KA, Babu KM, Hack JB. Methadone, another cause of opioid-associated hearing loss: a case report. J Emerg Med. 2011;41(6):635-9. 
14. Oh AK, Ishiyama A, Baloh RW. Deafness associated with abuse of hydrocodone/acetaminophen. Neurology. 2000;54(12):2345.

15. Kuhn M, Heman-Ackah SE, Shaikh JA, Roehm PC. Sudden sensorineural hearing loss: a review of diagnosis, treatment, and prognosis. Trends Amplif. 2011;15(3):91-105.

16. Saifan C, Glass D, Barakat I, El-Sayegh S. Methadone induced sensorineural hearing loss. Case Rep Med. 2013;2013:242730.

17. Chau JK, Lin JR, Atashband S, Irvine RA, Westerberg BD. Systematic review of the evidence for the etiology of adult sudden sensorineural hearing loss. Laryngoscope. 2010;120(5):1011-21.

18. Lupin A, Harley C. Inner ear damage related to propoxyphene ingestion Can Med Assoc J. 1976;114(7):596

19. Harell M, Shea JJ, Emmett JR. Total deafness with chronic propoxyphene abuse. Laryngoscope. 1978;88(9):1518-21.

20. Mulch G, Handrock M. "Sudden binaural deafness" after acute heroin intoxication (author's transl). Laryngol Rhinol Otol. 1979;58(5):435-7.

21. Ishiyama A, Ishiyama G, Baloh RW, Evans CJ. Heroin-induced reversible profound deafness and vestibular dysfunction. Addiction. 2001;96(9):1363-4.

22. Schrock A, Jakob M, Wirz S, Bootz F. Sudden sensorineural hearing loss after heroin injection. Eur Arch Otorhinolaryngol. 2008;265(5):603-6.

23. Nair EL, Cienkowski KM, Michaelides E. The impact of sudden hearing loss secondary to heroin overdose on fitting outcomes. Am J Audiol. 2010;19(2):86-90.

24. Van Gaalen F, Compier E, Fogteloo A. Sudden hearing loss after a methadone overdose. Eur Arch Otorhinolaryngol. 2009;266(5):773-4.

25. Christenson BJ, Marjala AR. Two cases of sudden sensorineural hearing loss after methadone overdose. Ann Pharmacother. 2010;44(1):207-10.

26. Jongkamonwiwat N, Phansuwan-Pujito P, Casalotti SO, Forge A, Dodson H, Govitrapong P. The existence of opioid receptors in the cochlea of guinea pigs. Eur J Neurosci. 2006;23(10):2701-11.

27. Jongkamonwiwat N, Phansuwan-Pujito P, Sarapoke P, Chetsawang B, Casalotti SO, Forge $\mathrm{A}$, et al. The presence of opioid receptors in rat inner ear. Hear Res. 2003;181(1-2):85-93.

28. Aulet RM, Flis D, Sillman J. A case of heroin induced Sensorineural hearing loss. Case Rep Otolaryngol. 2014;2014:962759. https://doi.org/10.1155/2014/ 962759

29. Hsu WY, Chiu NY, Liao YC. Rhabdomyolysis and brain ischemic stroke in a heroin-dependent male under methadone maintenance therapy. Acta Psychiatr Scand. 2009;120(1):76-9.

30. Corliss RF, Mandal R, Soriano BJ. Bilateral acute necrosis of the globi pallidi and rhabdomyolysis due to combined methadone and benzodiazepine toxicity. Am J Forensic Med Pathol. 2013;34(1):1-4.

31. Hojs R, Sinkovič A. Rhabdomyolysis and acute renal failure following methadone abuse. Nephron. 1992;62(3):362.

32. Nanji AA, Filipenko JD. Rhabdomyolysis and acute myoglobinuric renal failure associated with methadone intoxication. J Toxicol Clin Toxicol. 1983 Jun;20(4):353-60

\section{Publisher's Note}

Springer Nature remains neutral with regard to jurisdictional claims in published maps and institutional affiliations.

Ready to submit your research? Choose BMC and benefit from:

- fast, convenient online submission

- thorough peer review by experienced researchers in your field

- rapid publication on acceptance

- support for research data, including large and complex data types

- gold Open Access which fosters wider collaboration and increased citations

- maximum visibility for your research: over $100 \mathrm{M}$ website views per year

At BMC, research is always in progress.

Learn more biomedcentral.com/submissions 